\title{
Simulation and Experimental Analysis of an Impulse Voltage Generator
}

\author{
Carlos Favela ${ }^{1}$, , Jesus Gonzalez ${ }^{1}$, Jose Hernandez-Avila ${ }^{2}$, Marco Arjona ${ }^{1}$, Concepcion Hernandez ${ }^{1}$, \\ Esau Caro ${ }^{1}$
}

${ }^{1}$ National Technology Institute of Mexico Campus La Laguna. Torreon, Coahuila, Mexico

${ }^{2}$ Energy Department, Metropolitan Autonomous University Campus Azcapotzalco, Mexico City, Mexico

Email address:

carlosfa1186@gmail.com (C. Favela)

${ }^{*}$ Corresponding author

\section{To cite this article:}

Carlos Favela, Jesus Gonzalez, Jose Hernandez-Avila, Marco Arjona, Concepcion Hernandez, Esau Caro. Simulation and Experimental Analysis of an Impulse Voltage Generator. Journal of Electrical and Electronic Engineering. Vol. 9, No. 4, 2021, pp. 93-99. doi: $10.11648 /$ j.jeee.20210904.11

Received: June 19, 2021; Accepted: June 28, 2021; Published: July 6, 2021

\begin{abstract}
This paper presents the simulation and experimental analysis of an impulse voltage generator (IVG) used for atmospheric discharge voltage tests. The electrical equivalent circuit of the IVG was simulated using the electromagnetic transients program EMTP-VR. Besides the simulation of the generator operation, it was necessary to make a detailed revision of the IVG components and determine their working condition to carry the laboratory experiments. The lack of a high DC voltage source to feed the IVG led to developing a high-voltage dc supply. Although the IVG was designed and built in February 1982, this equipment was out of operation due to its DC power supply failure. Due to the interest in rehabilitating the equipment to perform high voltage experiments, and with the need to characterize insulation materials and electrical equipment subject to electrical stress, it was decided to put it back into operation. Capacitor tests were carried out for each IVG stage to determine if they fulfilled the electrical charging function. Other components were also repaired, such as damaged resistances and sphere gaps. The impulse generator was configured with a maximum of six stages which is half of the original design. Before doing an experiment with the IVG, a simulation analysis was made to study the IVG. The simulation results allow evaluating before the experimentation whether the impulse generator is working correctly; the model allows to analyze the charge and discharge of each capacitor and the electrical currents at each branch of the IVG equivalent circuit. Performance Simulation and experimental results are presented to demonstrate the IVG functionality. The IVG will be used for carrying out insulation tests made by power engineering graduate students.
\end{abstract}

Keywords: Impulse Voltage Generator, Voltage Transients, Dielectrics

\section{Introduction}

An impulse high-voltage voltage generator with twelve reconfigurable stages up to $720 \mathrm{kV}$ is employed to evaluate the insulation level of electrical equipment. The generator was initially built for academic and research purposes where electrical components, electrical equipment, and insulating materials employed at high voltage levels were tested $[1,2]$. Some procedures and standards for testing electrical insulation elements are described in [3-8]. References [9] and [10] present the design and simulation of an IVG using the ATP simulation software.
This equipment was designed such as its characteristics of applied voltage and discharge current can be modified easily by quickly changing the array of capacitors and resistors during the generator charging stage.

Some components found in poor working conditions were repaired, e.g., resistors, capacitors, connectors, and cables. The lack of maintenance was detected in most of the IVG elements. Therefore it was necessary to replace some parts that were in poor operating conditions. Electrical measurements were made to verify the working conditions of components, mainly the capacitors and load resistors corresponding to the voltage multiplier stages and 
spinterometers (spheres of a discharge switch or spark-gaps). The properties and tests of these elements used as ultra-fast switches are explained in [11]. The impulse voltage generator reproduces similar transients to those generated by atmospheric discharges presented in electrical power systems [12-15]. Therefore the IVG allows the characterization and analysis of insulating materials and prototypes of electrical equipment. In addition, it will enable the research on dielectric materials (solids, liquids, and gases).

This paper presents the modeling and simulation of the IVG operation; it shows the charging and discharging of its capacitors. It also explains the procedure developed to review the working conditions of the IVG components to carry laboratory tests. A design of a high-voltage dc power supply is also presented. Finally, high voltage experimental tests are shown that successfully demonstrate the IVG functionality.

\section{Impulse Voltage Generator}

The impulse voltage generator is mainly made of a network of capacitors and resistors. These elements perform several functions to generate high-voltage transient waveforms. High voltage pulses are generated to emulate atmospheric lightings or surges due to electrical switching operations. The IVG allows modifying the waveform characteristics such as front time to the maximum voltage amplitude, decay time to $50 \%$ of the amplitude, wave profile, etc. The experiments usually performed with an IVG in research laboratories vary considerably. They range from routine tests to determine the efficiency and reliability of materials and even studies of dielectric materials used in electrical equipment in special operating conditions. This equipment is employed in dielectric tests of insulating materials and electrical equipment. The tests performed with an IVG can be from hundreds to thousands of volts, and they are applied to equipment such as insulators, transformers, lighting rods, conductors, blades, generators, etc., $[16,17]$.

During an electrical transient, voltages and currents are generated. They are composed of signals of different frequencies that attenuate or appear as the transient evolves, i.e., the composition of voltage and current harmonics vary with time. The above is because the current in an inductor cannot change quickly, and the voltage at a capacitor does not instantaneously change due to the stored electrical charge. It takes a specific time to be redistributed in an electrical circuit.

The waveform of an impulse surge can be represented by a double exponential function which can be defined as:

$$
V=V_{0}[\exp (-\alpha t)-\exp (-\beta t)]
$$

Where $V$ is the voltage impulse, $V_{0}$ is the initial voltage, and $\alpha-\beta$ are waveform parameters.

An exponential waveform can be generated in the laboratory using RLC circuits in over-damping conditions or with the combination of RC circuits [18]. The different types of electrical networks that can create impulse waveforms are shown in Figure 1. These circuits are the most commonly used and are four basic models for obtaining different characteristics. The electrical circuits can reproduce transient voltages due to atmospheric lightings and those due to switching operations.
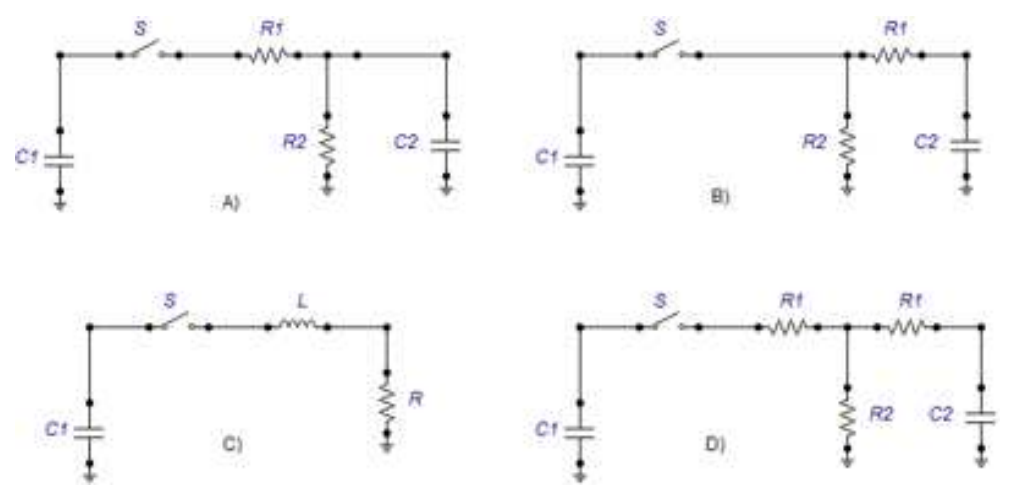

Figure 1. Electrical RC circuits that produce lightning-type waveforms. a, b, d) Commercially used circuits, and c) Circuit limited only to generator modeling.

Although other circuits can generate exponential voltage waveforms, which can be used as atmospheric voltage impulses, the electric circuit commonly used is formed by two capacitors, two resistors, and a switch. The main elements of an IVG are the following:

a) Main capacitor. It is a series capacitor of the Marx multiplier circuit (which consists of $\mathrm{N}$ inserted stages or coupled circuits, like those shown in Figure 1, also known as voltage bending). The capacitance and voltage of this element define the energy of an IVG. The main capacitor is always much larger than the output capacitor. This capacitor is connected to a high voltage DC source through a limiting resistor. Once it is charged, a switch is closed, causing the capacitor to be suddenly discharged, and the rest of the circuit receives this energy at a high voltage.

b) Output capacitor. It is the capacitance of the test object (power equipment, dielectric material, etc.) plus an additional capacitor. It must be an element with lower capacitance than the main capacitor, which stands the output voltage and the power associated with the IVG. The voltage impulse is applied to the output capacitor.

c) Front and tail resistors. The first stage resistor is connected in series to the main capacitor and to the switch. When the switch is closed, the current flows through this resistance. The tail resistance is connected parallel to the main capacitor when the switch is closed. 
d) Load resistance. It is used to limit the initial charging current. The load resistor has a high value to guarantee that no current flows through them during a discharge. A typical load current should be in the range of 50 and 200 $\mathrm{mA}$. The load resistor also allows a circulating current that keeps the flashover voltage alive in the sphere gap. It varies from 5 to $10 \mathrm{~A}$ through the spark gap.

e) Spark-gap. This element completes the electric circuit. It allows the discharge of the main capacitor since it is part of a resistive-capacitive network composed of the output capacitor, the front and tail stage resistors. This switch is primarily used in high voltage equipment and is formed by two separate metallic spheres. These hollow spheres, which are found in pairs at each IVG stage, are used as a switch mechanism that allows the discharge of the IVG capacitors. One sphere is installed in a fixed column made of an insulation material (bakelite), while the other sphere is mounted in a mobile column. All the gaps between the spheres must be equal. By increasing the space between the spheres, the capacitors of the IVG can be charged to a voltage level defined by the Paschen curves. The discharge of each of the stages is achieved by decreasing the gap.

f) Impulse generator trigger. It triggers the IVG at predefined charge conditions and at the desired time. It will enable the discharge in the first stage and successively in the remaining IVG stages and finally applies the full voltage waveform to the device under test.

The standardized profiles of impulse waveforms are the essential concepts that are applied in the generation and use of voltage and current pulses for testing high-voltage electrical equipment. A voltage impulse is a short-time transient voltage waveform with a unique polarity obtained with the electric breakdown of air. Without considering the fast oscillations, the output characteristic increases rapidly to a maximum value and decreases to zero. This curve is presented in Figure 2, and it is defined by its peak value, polarity, and characteristic time parameters. The full voltage waveform or lightning impulse is a voltage impulse that reaches the peak value in $1.2 \mu \mathrm{s}$ and decreases exponentially slowly to zero, with a time to the half value tail of $50 \mu \mathrm{s}(1.2 / 50 \mu \mathrm{s})$.

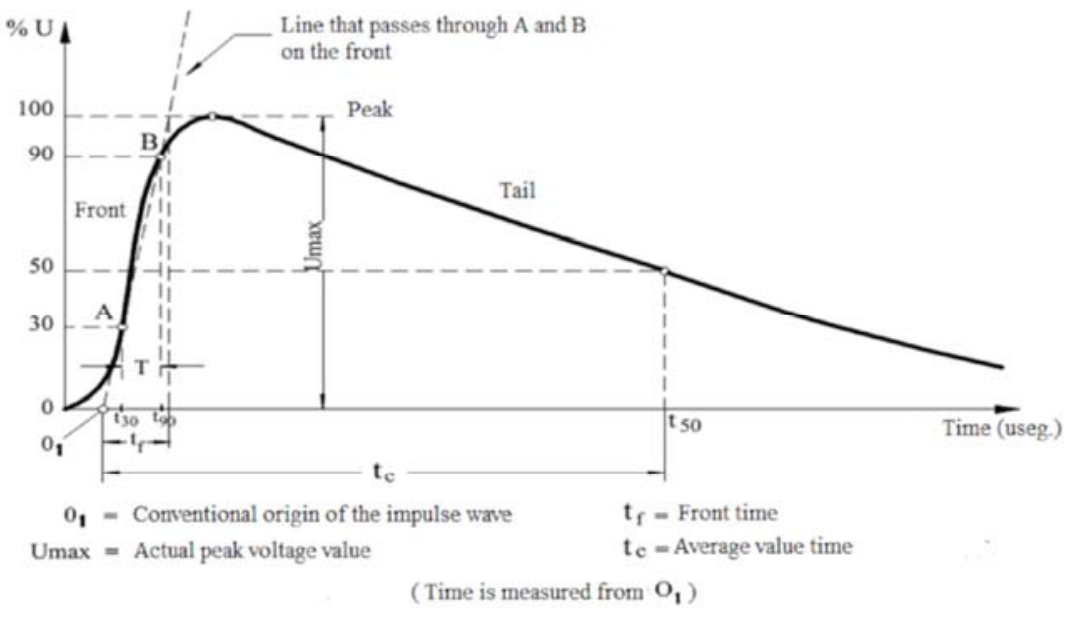

Figure 2. Characteristic of the full impulse voltage waveform.

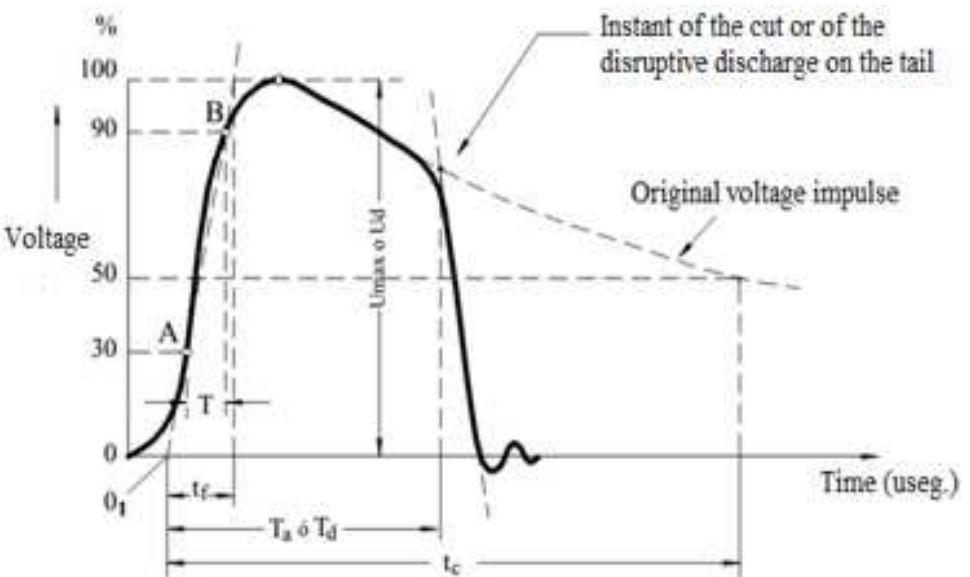

$\mathrm{Ta}=$ Cut-off time when the initial discontinaity or the occurrence of the dissuptive discharge occurs

$\mathrm{T}_{\mathrm{d}}=$ Instant when the disruptive discharge occurs in the test object

$U_{d}=$ Dissuptive volage on the voltage impulse

Figure 3. Characteristic of the chopped voltage tail impulse. 
A chopped impulse voltage is a waveform that, after 2 or 3 $\mu \mathrm{s}$ is quickly cut off by a disruptive load; this produces a sudden voltage drop to zero. The impulse voltage cut-off can be made by employing a particular switch, or it can be generated due to a discharge in the insulation of a test device; this is shown in Figure 3. The waveform voltage impulse is chopped at the front, and the voltage increases with an approximately constant slope until it is cut-off at the front by a disruptive discharge, as shown in Figure 4.

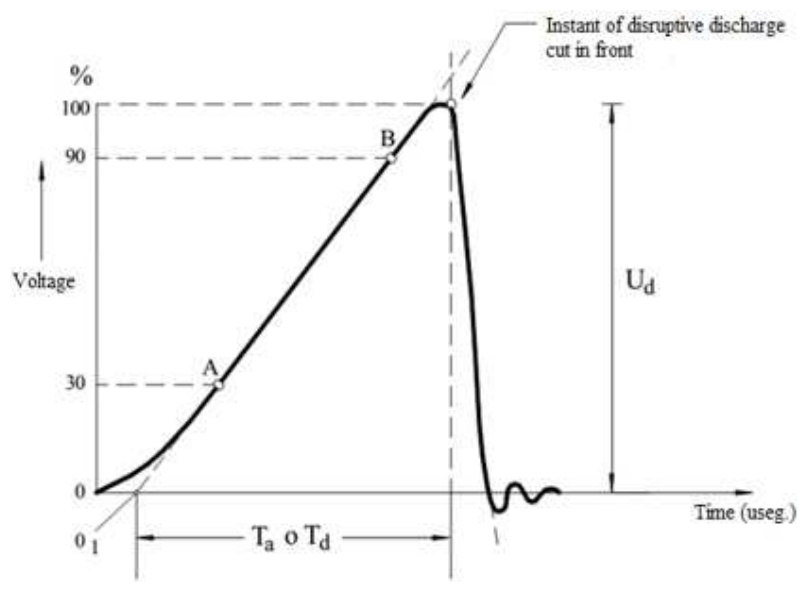

Figure 4. Characteristic of a disruptive voltage impulse.

\section{IVG Components}

The IVG components presented a severe lack of maintenance, and a large amount of dust, oil, grease, and oxidation was found in the support columns, stage capacitors, spheres, connectors, bridges, and cables. The design data of the IVG are shown in Table 1 (numbers of stages, each capacitor represents an IVG stage, the number of IVG configurations is 12 stages).

The power supply of the IVG was damaged, and this was why the IVG was out of operation. The stage capacitors were found in optimal operating conditions (Figure 5). However, there were minor damages to the structure, chassis, and electrical terminals. The IVG has 12 tail $1500 \Omega$ resistors and 36 front resistors (12 of $50 \Omega, 12$ of $120 \Omega$ and 12 of $300 \Omega$ ). The resistances are made of Nichrome wire because it is a material that stands at high temperatures and keeps its resistance value under temperature changes. Although, in general, most resistors were in good operating conditions, a few of them had worn on the wires, while others showed corrosion and sparking at their terminals. The load or limiting resistors are 11 each with a value of $45 \mathrm{k} \Omega$. Figure 6 shows the front, tail, and load IVG resistances.

Table 1. Design data of the IVG.

\begin{tabular}{ll}
\hline Description & Value \\
\hline Lighting impulse waveform & $1.2 / 50 \mu \mathrm{s}$ \\
Supply voltage & $120 \mathrm{~V}$ \\
Rated voltage $\left(\mathrm{V}_{\mathrm{n}}\right)$ & $720 \mathrm{kV}$ \\
Rated energy $(\mathrm{U})$ & $\mathrm{U} \approx 1 \mathrm{~kJ}$ \\
14 capacitors & $\mathrm{C}=45 \mathrm{nF}$ of $60 \mathrm{kV}$ \\
\hline
\end{tabular}

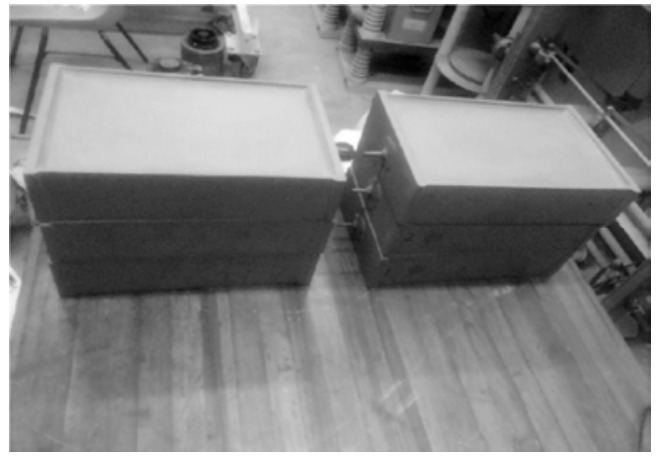

Figure 5. Capacitors of the IVG.

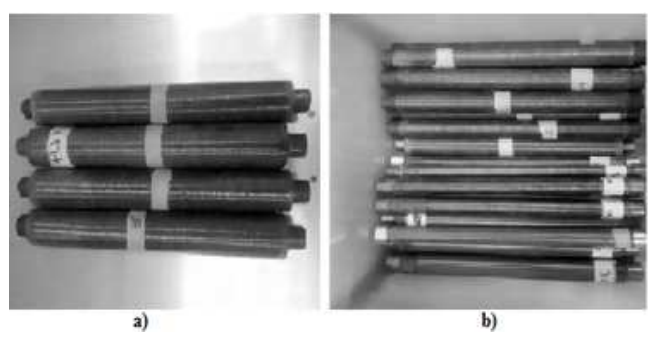

Figure 6. a) Load resistors and b) front and tail resistors.

The sphere gaps are made of copper and are mounted on two columns (one mobile and the other fixed) that had dents and erosion on their surfaces, as shown in Figure 7. The marks were formed due to a large number of IVG tests.

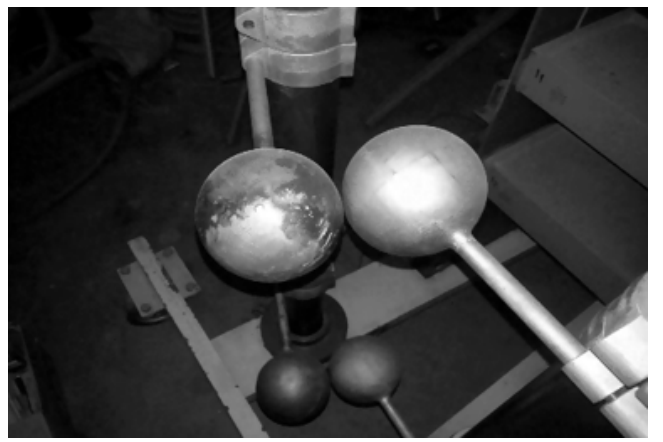

Figure 7. IVG spheres with a $10 \mathrm{~cm}$ diameter.
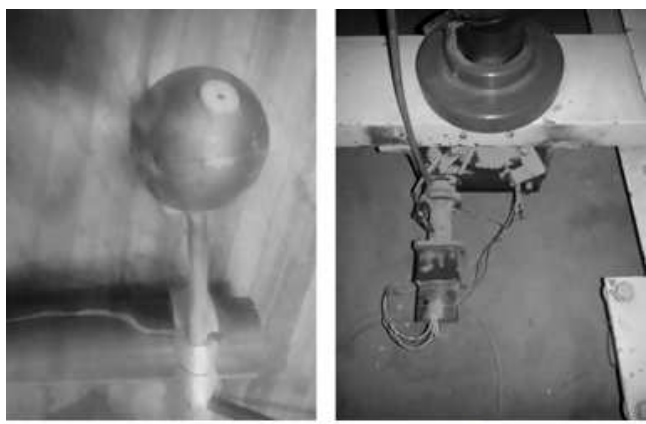

Figure 8. a) Triggering component of the IVG and b) stepper motor for the sphere movement.

There is also a stepper motor to move the sphere gaps to trigger the IVG, as shown in Figure 8. The IVG has a trigatron gap that allows starting the spark between the spinterometer 
spheres and the discharge of the capacitors at the different IVG stages.

Developing a high-voltage power supply was necessary because the original high DC voltage source that supplies the voltage to the IVG presented a failure in its control unit [19-22]. In designing the new high DC voltage power supply, a high-voltage rectifier bridge was developed and high-voltage transformers to achieve the electric potential needed for charging the capacitors. The bridge was constructed using $40 \mathrm{kV}$ diodes (Tesla Ham 2CLG40KV/1 A). A fast-operating fuse array $(750 \mathrm{~mA})$ was adapted to the rectifier to protect the diodes. The full-wave rectifier bridge is shown in Figure 9.
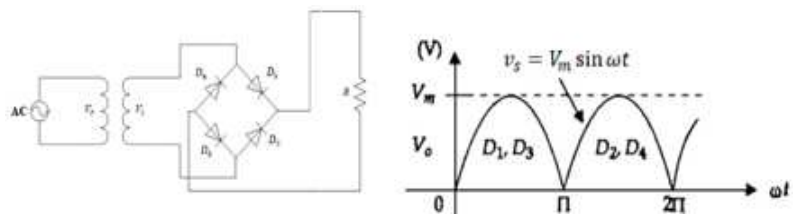

Figure 9. Electrical circuit and waveform of the high-voltage rectifier.

\section{Simulation of IVG Operation}

The IVG performance was simulated using the EMTP-VR software. The IVG mathematical model is an electrical equivalent circuit with values of capacitances and front and tail resistances. The IVG was designed to operate using 12 stages; due to working problems of some of its elements, it was adapted to operate with only six stages. The equivalent circuit of the IVG with the Marx six-stage circuit will define the standard voltage waveform. Figure 10 shows the equivalent electric circuit, which represents the complete diagram of the IVG. It consists of a high voltage transformer, a high-voltage rectifier bridge that feeds the network of capacitors and resistors.

Figures 11 and 12 illustrate the dynamic behavior of the charging process of capacitors where the charging time is clearly seen. It is observed that the waveform of the three capacitors oscillates as they are charged, while in the following three capacitors, the voltage waveforms are more stable. Thus, when a capacitor is triggered, the voltage tends to zero in a short time.

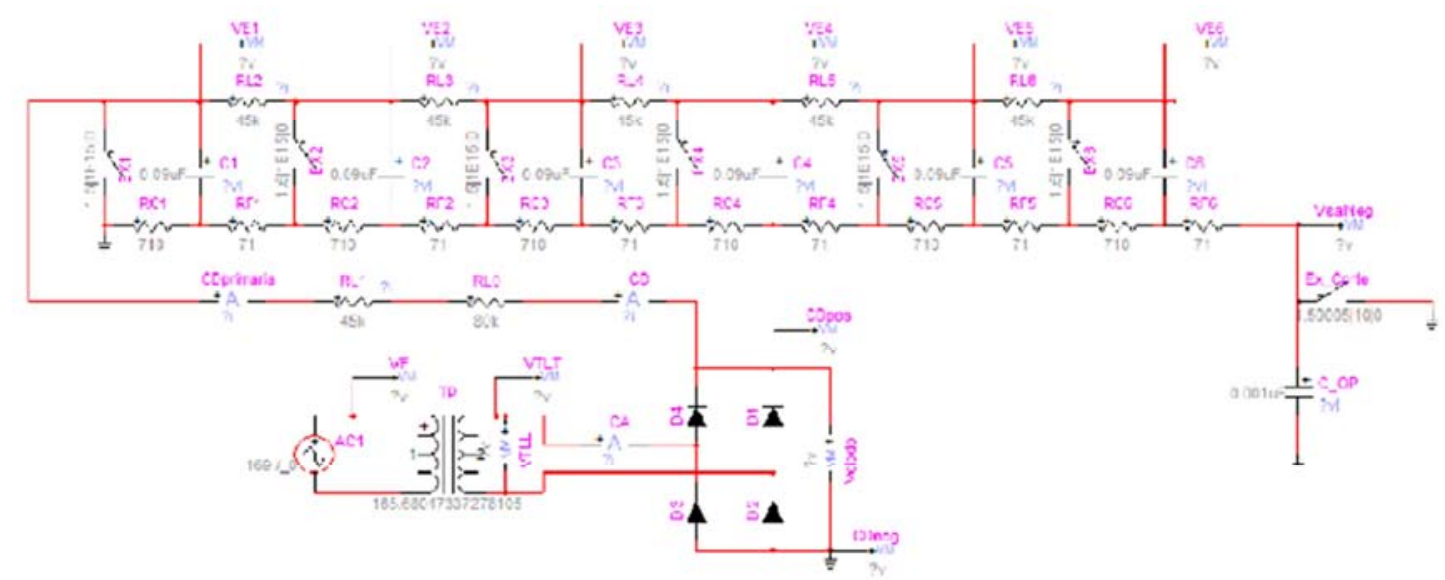

Figure 10. High-voltage dc power supply and the equivalent electrical circuit of the IVG.

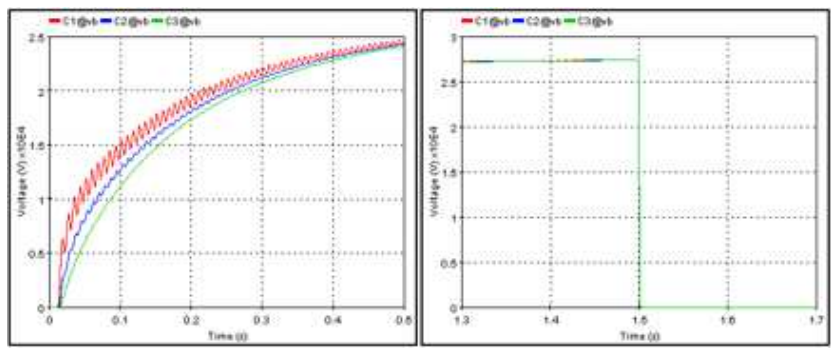

Figure 11. a) Charge and b) discharge of capacitors 1, 2, and 3.

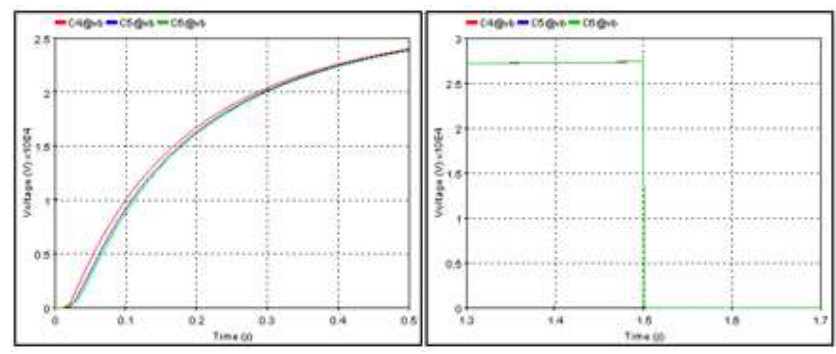

Figure 12. a) Charge and b) discharge of capacitors 4, 5, and 6.

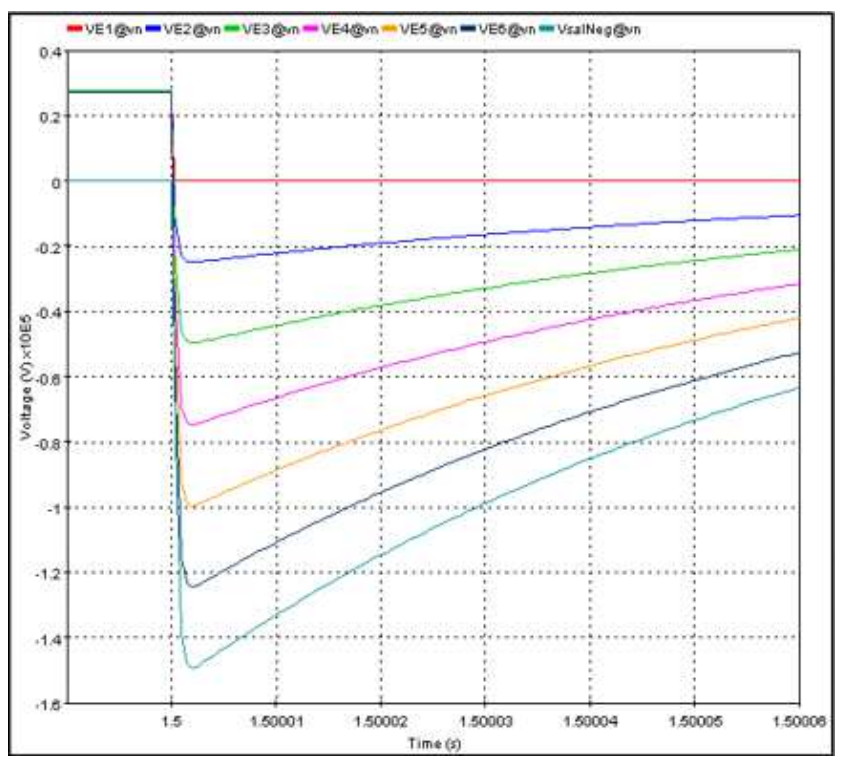

Figure 13. Voltages at each stage of the $I V G$. 


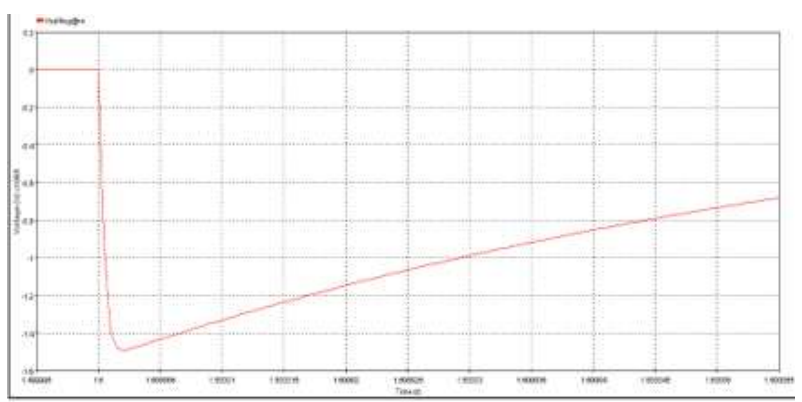

Figure 14. Full impulse voltage waveform.

Figure 13 shows the total voltage at each stage of the IVG, and all the waveforms have the normalized values, such as the front and tail times for the standard $1.2 / 50 \mu \mathrm{s}$ for voltage impulses due to lightning phenomena. Due to the IVG configuration, it inverts the polarity of the voltage, so the output voltage is negative; for this reason, the impulse signal is seen reversed (Figure 14). The waveforms obtained in the simulations indicate the correct performance of the different IVG stages. The simulation results allow confidence because actual values of resistances, capacitances, and voltage levels were used to model the electrical equivalent circuit of the IVG.

\section{IVG Experimental Results}

The starting up of the IVG consists mainly of obtaining the impulse voltage waveform measured on a load. For this purpose, a capacitor capable of withstanding voltages up to $200 \mathrm{kV}$ was used. In addition, an intermediate metallic plate was inserted into the test capacitor, which allows us to obtain a voltage ratio of $10: 1$, i.e., when a $100 \mathrm{kV}$ impulse is applied, the value measured on the intermediate plate is $10 \mathrm{kV}$. The above allows taking measurements of high voltage tests without being limited by the rating voltage of the attenuator probe that is $40 \mathrm{kV}$ (Tektronix P6015A).

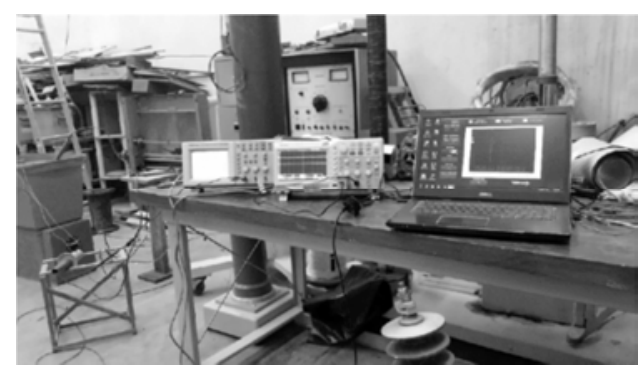

Figure 15. Impulse voltage measurement with a high-voltage probe.

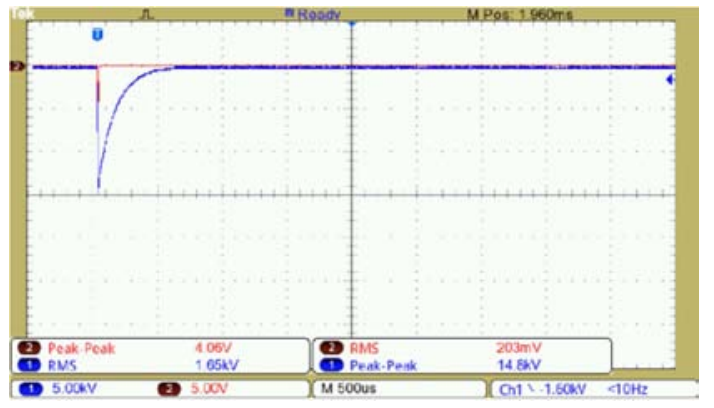

Figure 16. Experimental voltage impulse of $14 \mathrm{kV}$ using two stages.

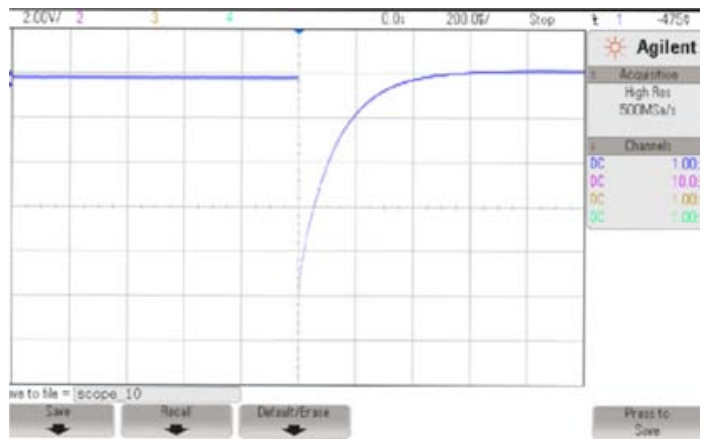

Figure 17. Experimental voltage impulse of $105 \mathrm{kV}$ using six stages.

Figure 15 shows the connection of the attenuator probe to the capacitor input or the intermediate plate depending on the voltage level to take readings in the oscilloscope of the impulse waveforms. Figure 16 illustrates the lightning voltage

impulse applied to a test capacitor with a peak value of 14 $\mathrm{kV}$ using only two stages of the IVG. The voltage of $105 \mathrm{kV}$ is shown in Figure 17, including the six stages of the IVG.

The values shown in Table 2 are the voltage measurements used in the laboratory experiments. The impulse values are equal to those observed in the oscilloscope plots obtained from each test performed. The physical aspect of the IVG and its operation is shown in Figure 18. When the gap between the spheres is reduced, the stage capacitors are discharged. The voltage of each stage is added to the next IVG stage because the capacitors are discharged in series. At the end of the electric circuit, the full voltage impulse is applied to the dielectric under test. The voltage waveform is acquired using the high-voltage probe and the oscilloscope.

Table 2. Voltage values used in the experiments.

\begin{tabular}{llll}
\hline $\begin{array}{l}\text { Low Voltage } \\
\text { input }(\mathbf{V})\end{array}$ & $\begin{array}{l}\text { Output transformer } \\
\text { voltage }(\mathbf{k V})\end{array}$ & $\begin{array}{l}\text { Rectified } \\
\text { voltage }(\mathbf{k V})\end{array}$ & $\begin{array}{l}\text { Impulse } \\
\text { voltage }(\mathbf{k V})\end{array}$ \\
\hline 16 & 1.5 & 2 & 12.5 \\
19 & 2.5 & 3.5 & 20 \\
22 & 3.5 & 5 & 30 \\
28 & 4.3 & 6 & 35 \\
30 & 4.6 & 6.5 & 40 \\
37 & 5.3 & 7.5 & 45 \\
49 & 8.8 & 12.5 & 75 \\
65 & 12.4 & 17.5 & 105 \\
\hline
\end{tabular}

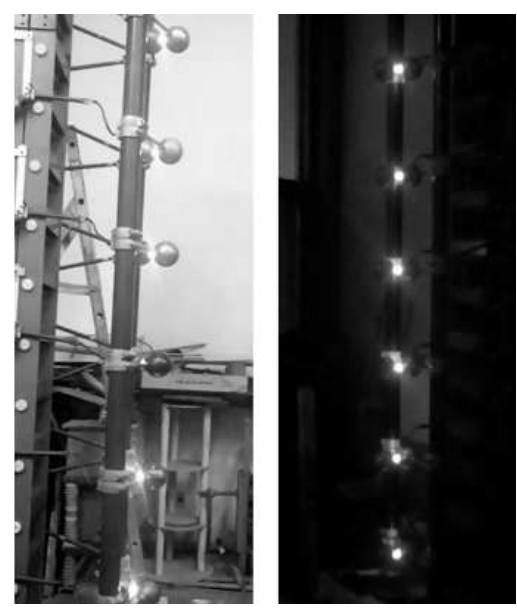

Figure 18. Experimental IVG triggering and the discharge of its capacitors. 


\section{Conclusions}

In this paper, the analysis of an impulse voltage generator was presented. The IVG components were evaluated as well as their integral operation by generating an impulse voltage of $1.2 / 50 \mu \mathrm{s}$. Furthermore, the electric transient simulation of the IVG was performed where the capacitors, front and tail resistors, and load capacitor were modeled. The simulation of the IVG operation was based on the modeling of the set of passive and linear electrical IVG elements. The transient IVG simulations allowed us to compare the impulse voltage signals with those obtained with experiments. The current working condition of this IVG is essential because it will enable high voltage engineering graduate students to carry out research experiments. Furthermore, as future work includes improving the IVG trigger, this will allow obtaining better control of discharge and the setup of the IVG twelve-stage configuration.

\section{Acknowledgements}

The authors wish to thank Fondo Sectorial de Sustentabilidad Energetica CONACYT-SENER, INEEL, CONACYT, National Technology Institute of Mexico Campus La Laguna, and Metropolitan Autonomous University Campus Azcapotzalco for their financial support under grant No. 206842 to carry out this research.

\section{References}

[1] F. S. Edwards, A. S. Husbands and F. R. Perry, "The development and design of high-voltage impulse generators," Proceedings of the IEE - Part II: Power Engineering, vol. 98, no. 64, pp. 570-571, August 1951.

[2] J. A. Vasquez, J. Zirnheld, K. Burke, V. Foley and W. J. Sarjeant, "Non-destructive examination of impulse generator pulses," in Digest of Technical Papers. 11th IEEE International Pulsed Power Conference (Cat. No. 97CH36127), Baltimore, MA, USA, 1997, pp. 1513-1518, vol. 2.

[3] IEEE Test Procedure for Impulse Voltage Tests on Insulated Conductors," IEEE Standard 82-1963, 1963.

[4] M. Khalifa, "High-voltage engineering, theory and practice," Marcel Dekker, 1990.

[5] E. Kuffel, W. S. Zaengl, J. Kuffel, "High voltage engineering fundamentals," Newness Press, 2000.

[6] High Voltage Test Techniques, Part 1: General Definitions and Test Requirements, IEC Standard 60060-1, 2010.

[7] High-voltage test techniques, part 2: measuring systems, IEC Standard 60060-2, 2010.

[8] High-Voltage Testing Techniques - Redline, IEEE Standard 4-2013 (Revision of IEEE Std 4-1995) - Redline, 2013.
[9] V. Rai, K. Pandey and K. Wadhwa, "Designing of multistage impulse voltage generator using ATP software," in 2015 International Conference on Recent Developments in Control, Automation and Power Engineering (RDCAPE), Noida, 2015, pp. 276-279.

[10] K. Veisheipl, "Simulation of the high voltage impulse generator," in 2016 17th International Scientific Conference on Electric Power Engineering (EPE), Prague, 2016, pp. 1-5.

[11] R. Montaño, M. Becerra, V. Cooray, M. Rahman and P. Liyanage, "Resistance of Spark Channels," IEEE Trans, on Plasma Science, vol. 34, no. 5, pp. 1610-1619, Oct. 2006.

[12] T. R. McComb and J. E. Lagnese, "Calculating the parameters of full lightning impulses using model-based curve fitting," IEEE Trans. on Power Delivery, vol. 6, no. 4, pp. 1386-1394, Oct. 1991.

[13] F. W. Heilbronner, "Firing and Voltage Shape of Multistage Impulse Generators," IEEE Trans. on Power Apparatus and Systems, vol. PAS-90, no. 5, pp. 2233-2238, Sept. 1971.

[14] S. Janaki and S. Yellampalli, "Design of impulse distributed waveform generator," in 2013 Fourth International Conference on Computing, Communications and Networking Technologies (ICCCNT), Tiruchengode, 2013, pp. 1-6.

[15] J. Hlavacek and M. Knenicky, "Very fast high voltage impulse generator," in 2018 19th International Scientific Conference on Electric Power Engineering (EPE), Brno, 2018, pp. 1-4.

[16] C. Pereira Braz and A. Piantini, "Analysis of the dielectric behavior of distribution insulators under non-standard lightning impulse voltages," IEEE Latin America Trans., vol. 9, no. 5, pp. 732-739, Sept. 2011.

[17] Bo Zhu, Xinlao Wei, Hongyan Nie, "Simulation research on on-line multi-parameter monitoring for long distance three-phase power cable," Journal of Electrical and Electronic Engineering, vol. 7, no. 5, pp. 126-133, Nov. 2019.

[18] F. C. Creed, M. M. C. Collins, 'Shaping circuits for high impulses," National Research Council of Canada Radio and Electrical Engineering Division Ottawa, Canada, 1971.

[19] M. B. J. Leusenkamp, "Impulse Voltage Generator design and the potential impact on Vacuum Interrupter de-conditioning," in 2012 25th International Symposium on Discharges and Electrical Insulation in Vacuum (ISDEIV), Tomsk, 2012, pp. 453-456.

[20] B. T. McCuistian and L. L. Hatfield, "Noise reduction of Marx generator erection," in Digest of Technical Papers. 11th IEEE International Pulsed Power Conference (Cat. No. 97CH36127), Baltimore, MA, USA, 1997, pp. 1680-1684 vol. 2.

[21] S. M. Turnbull, S. J. MacGregor, F. A. Tuema and J. Harrower, "The repetitive operation of a spark gap column," in Digest of Technical Papers. 11th IEEE International Pulsed Power Conference (Cat. No. 97CH36127), Baltimore, MA, USA, 1997, pp. 899-904 vol. 2.

[22] D. F. Garcia Gomez, E. Marles Saens, T. A. Prado and M. Martinez, "Metodology for Lightning Impulse Voltage Divisors Design," IEEE Latin America Trans., vol. 7, no. 1, pp. 71-77, March 2009. 